\title{
Characterizing the Antibiotic Resistance Patterns of Microbes Isolated from Wildlife Presented to the Wildlife Hospital of Louisiana (Baton Rouge, LA)
}

\author{
Mark Mitchell, DVM, MS, PhD; Emily Dahlgran, BS; Alma Roy, MS, PhD \\ LOUISIANA STATE University, BATON ROUGE, LOUSIANA
}

\begin{abstract}
The isolation of antimicrobial resistant bacteria (ARB) from humans and livestock is a special concern for public health officials. Although research has been conducted to evaluate the prevalence of ARB in human and veterinary hospitals, there has been limited research evaluating the potential for ARB in wildlife and wildlife hospitals. The purpose of this study was to determine the prevalence of ARB in wildlife presented to the Wildlife Hospital of Louisiana (WHL). Seventy percent (19/27) of the wildlife presented to the WHL during the summer of 2002 had ARB bacteria. In addition, 40 percent $(15 / 37)$ of the samples collected from within the hospital environment also were found to harbor ARB. Antibiotic resistant bacteria pose a health risk for compromised patients and their human caretakers in a wildlife hospital. Management plans should be developed within wildlife rehabilitation facilities to decrease the likelihood of creating and disseminating ARB.

Key Words: antibiotic resistance, bacteria, Louisiana, microbes, wildlife
\end{abstract}

\section{INTRODUCTION}

The isolation of antimicrobial resistant bacteria (ARB) from human hospitals has generated a great deal of interest among health professionals. The Centers for Disease Control and Prevention (CDC) estimate that approximately two million humans acquire infections while in a hospital, and these hospital-acquired infections account for approximately 90,000 human deaths per year (Borchardt 2001; Bren 2002). Antibiotic resistant bacteria are isolated from approximately 70 percent of these cases (Bren 2002). Nosocomial (hospital-acquired) infections have also been reported in veterinary hospitals (Cooke et al 2002).

In veterinary medicine, as in human medicine, antibiotics are frequently prescribed for cases without a confirmed bacterial infection. The widespread use of antibiotics to manage clinical cases can lead to the development of ARB within the host. The transient

Dr. Mitchell is a former member of the NWRA Board of Directors. $\mathrm{He}$ is Assistant Professor of Zoological Medicine and Director of the Wildlife Hospital of Louisiana at the Louisiana State University. Emily Dahlgran is a fourth year veterinary student at Louisiana State University School of Veterinary Medicine and will be graduating in May 2005.

Dr. Roy is Assistant Professor in Pathobiological Sciences at Louisiana State University. shedding of these organisms can lead to the dissemination of these microbes to additional hosts and the environment. The establishment of ARB in secondary and tertiary hosts, and the environment, likely provides the primary route of transmission of $A R B$ in hospital settings (O’Brien 2002).

The widespread use of antibiotics as growth promoters for livestock has also been implicated in the transmission of ARB. The CDC have estimated that 20 million pounds of antibiotics are provided to livestock and poultry annually as growth promoters, and that approximately 80 percent of all livestock and poultry receive antibiotics in their food at some point during their production (Hileman 1999). Subtherapeutic levels of antibiotics have been found to increase growth efficiency for swine and poultry, and improve profits (Braude et al 1955; Sims et al 2004). However, the use of subtherapeutic antibiotics can also lead to the development of ARB in these animals. At the time of slaughter, carcass contamination with ARB can lead to the introduction of the microbes into the human food supply.

Antimicrobial resistance generally occurs when bacteria produce a protein that inhibits the function of a specific antibiotic (O'Rourke 2003). Bacteria develop resistance to antibiotics through mutations in their chromosomes or from the acquisition of resistance genes from other microbes, as with the transfer of plasmids. The transfer of antibiotic resistance through plasmids is not a recent event, as bacteria have evolved to produce natural antimicrobial materials as a defense mechanism against other microbes. However, since the advent of man-made antibiotics in the twentieth century, the selection for ARB has appeared to increase dramatically.

Although there have been studies evaluating the presence of ARB in human and veterinary hospitals, there has been only limited research evaluating ARB in wildlife (Hudson et al 2000), and the majority of 
these reports have been associated with captive exotic species (Bailey et al 1998; Kimpe et al 2002). Hudson et al (2000) isolated Salmonella from a goldfinch and an owl that were resistant to sulfamethoxazole. The findings of ARB in wildlife suggest that wildlife may serve as sentinels for ARB in the environment, and that research to further characterize the role of wildlife in the dissemination and translocation of ARB is necessary.

The purpose of this study was to determine the prevalence of $\mathrm{ARB}$ in adult wildlife presented to the Wildlife Hospital of Louisiana (WHL) (Baton Rouge, LA) and the WHL environment. The specific hypotheses tested in this study were: 1) greater than 25 percent of the wildlife presented to the WHL would have antibiotic resistance (AR) to at least one antibiotic; 2) AR would occur most commonly in those compounds (doxycycline, penicillin) that have been used the longest in human and veterinary medicine; 3) AR patterns for bacteria isolated from wildlife would be similar to those for the bacteria found in the hospital environment.

\section{MATERIALS AND METHODS}

A cross-sectional study was conducted from May 24 to August 21, 2002 at the Wildlife Hospital of Louisiana to characterize the prevalence of ARB in wildlife.

Recruitment for the study was limited to adult avian, mammalian, and reptilian wildlife that presented to the WHL. Cloacal or rectal samples were collected from each patient within two hours of presentation. All samples were collected with a sterile, cotton-tipped applicator before the patient received any treatment. The sample was streaked onto five percent sheep blood (BA) (Remel, Lenexa, KS) and MacConkey agars (Remel, Lenexa, KS), and incubated for 48 hours at $37^{\circ} \mathrm{C}$ under aerobic conditions. After incubation, distinct colonies were selected from the plates and Gram-stained. Gram-positive, coagulase positive Staphylococcus and Gram-negative rods were further characterized using standard biochemical media. Once characterized, the isolates were transferred to five percent BA and incubated for 18 hours at $37^{\circ} \mathrm{C}$ under aerobic conditions. The standard Kirby Bauer Disc Diffusion method was performed using well-isolated colonies of the same morphological type (National Committee for Clinical Laboratory Standards [NCCLS] 2002). The direct colony suspension method was performed by picking isolates from an 18 to 24 hour agar plate, and diluting them in $0.9 \mathrm{ml}$ of sterile saline to match the turbidity of a $0.5 \mathrm{McF}$ arland standard. Mueller Hinton agar plates (Remel, Lenexa, $\mathrm{KS}$ ) were inoculated by spreading the inoculum over the entire agar surface with a swab. Eleven antibiotics were used in the sensitivity testing, including amikacin (AM) $(30 \mu \mathrm{g})$, cefatoxime (CTX) $(30 \mu \mathrm{g})$, ceftazidime (CAZ) $(30 \mu \mathrm{g})$, chloramphenicol (C) $(30 \mu \mathrm{g})$, ciprofloxacin (CIP) $(5 \mu \mathrm{g})$, doxycycline (D) $(30 \mu \mathrm{g})$, enrofloxacin (ENO) $(5 \mu \mathrm{g})$, gentamicin $(\mathrm{GM})(10 \mu \mathrm{g})$, piperacillin (PIP) $(10 \mu \mathrm{g})$, ticaricillin (TIC) $(75 \mu \mathrm{g})$, and trimethoprim sulfadimethoxine (SXT) (1.25/23.75 $\mu$ g). The antimicrobial sensitivity plates were incubated for 18 hours at $37^{\circ} \mathrm{C}$ under aerobic conditions. The zone of inhibition for each antibiotic disk was determined using a metric ruler. Bacteria were classified as resistant according to NCCLS regulations (NCCLS 1993). Controls for the Kirby Bauer method described in this study used both Gram-positive and Gram-negative ATCC strains of bacteria, and were performed weekly as recommended by the NCCLS (2002).

Bacteriologic samples were also collected from the WHL environment. Sterile cotton-tipped applicators were used to collect weekly samples from the surfaces of the two counters in the hospital ward, six cages used to house wildlife, two exam tables, floor surface, the interior surfaces of the refrigerators used to store food for the animals and for drugs $\left(4.4^{\circ} \mathrm{C}\right)$, the food used to feed orphan passerines, three pairs of leather gloves used to restrain raptors, veterinary student hands and stethoscopes, and the surgical instrument storage tray. The surgical tray was filled with two percent chlorhexidine (Nolvasan ${ }^{\circledR}$ solution, Ft. Dodge Animal Health, Overland Park, KS), and the surgical instruments were used for minor diagnostic procedures. The chlorhexidine was changed one to two times per week. A 6-ml chlorinated water sample was also collected from the faucet in the ward, and the water inoculated directly onto the agar plates. A BA and MacConkey agar plate also were placed on the top of the shelving unit in the wildlife hospital to collect aerosolized bacteria. The plates were collected after 24 hours. The environmental samples were cultured using the techniques described previously.

The 95 percent binomial confidence intervals (CI) were calculated for each prevalence estimate. In cases where the prevalence estimate was zero, the 95 percent CI were calculated using the techniques described by van Belle and Millard (1998). Fisher's exact test was used to compare antimicrobial resistance patterns between the different bird groups. A p $<0.05$ was considered statistically significant.

\section{RESULTS}

A total of 51 samples were collected from wildlife for culture during the sampling period. Forty-four (86\%) samples were collected from birds, three $(6 \%)$ from 
Table 1. Bacteriologic samples were collected from the following avian, mammalian, and reptilian species.

Avian

Raptors

Barred owl

Mississippi kite

Broad-winged hawk

Great horned owl

Osprey

Eastern screech owl Otus asio

Red-shouldered hawk Buteo lineatus

Non-raptorial birds

Pigeon

Great egret

American crow

Blue jay

Northern cardinal

Great blue heron

European starling

Mute swan

Canada goose

Loggerhead shrike

Mammals

Eastern grey squirrel

Virginia opossum

Reptiles

Red-eared slider

Eastern box turtle

Snapping turtle
Red-tailed hawk
Buteo jamaicensis

Strix varia

Ictinia mississipiensis

Buteo platypterus

Bubo virginianus

Pandion haliaetus

Columba livia

Ardea alba

Corvus brachyrhynchos

Cyanocitta cristata

Cardinalis cardinalis

Ardea herodias

Sturnus vulgaris

Cygnus olor

Branta canadensis

Lanius ludovicianus

Sciurus carolinensis

Didelphis virginiana

(1)

Trachemys scripta elegans Terrapene carolina carolina 1 Chelydra serpentina also isolated from two barred owls (Strix varia) and a red-tailed hawk (Buteo jamaicensis).

Fifteen (40\%) of the thirty-seven Gramnegative rod isolates from the environment had at least intermediate antimicrobial resistance patterns. These were cultured from the refrigerator used to store food $(n=2)$, the wildlife cages $(n=2)$, the floor $(n=2)$, refrigerated food fed to orphan passerines $(\mathrm{n}=2)$, an air sample $(n=1)$, the refrigerator used to store drugs $(n=1)$, the leather restraint gloves $(n=1)$, the counter surface $(n=1)$, the exam table $(n=2)$, and the instrument sterilization tray $(\mathrm{n}=1)$ (Tables 3 and 4). Of the 27 wildlife isolates tested, 19 (70\%) demonstrated at least intermediate resistance patterns (Tables 5 and 6).

Antimicrobial resistance was recorded in all four coagulase positive Staphylococcus (Tables 3 and 4) isolated from the environment, while only one Staphylococcus species of the three isolated from raptors was resistant to antibiotics (Table 6). There was no significant difference in prevalence of antimicrobial resistance between raptors and waterfowl $(\mathrm{p}=0.63)$, raptors and passerines $(p=0.36)$, or passerines and waterfowl $(\mathrm{p}=0.73)$.

Two wildlife cases were sampled prior to release. An S. intermedius isolated from the prerelease sample taken from a red-tailed hawk was resistant to ceftazidime, and had intermediate susceptibility to amikacin and chloramphenicol. This patient was not treated with any antibiotics prior to its release. An S. intermedius isolated

Table 2. Bacteria isolated from wildife and the WHL environment that could be characterized to species.

139 samples were collected from the WHL environment for culture.

A total of 360 bacteria [210 (58\%) Gram-positive cocci, 89 (25\%) Gram-positive rods, and 61 (17\%) Gram-negative rods] were recovered from the patients and the environment. Antimicrobial sensitivity testing was only performed on the Gram-negative isolates $(n=61)$ and the coagulasepositive Staphylococcus species $(n=7)$ (Table 2). Seventeen of the Gram-negative isolates could not be characterized to genus. Antimicrobial sensitivity profiles were performed on 37 (61\%) Gram-negative rods from the environment and 24 (39\%) from the patients sampled. The Gram-negative isolates were isolated from raptors $(n=14)$, passerines $(n=6)$, waterfowl $(n=3)$, and one mammal. The coagulase positive Staphylococcus species were isolated from the hands of two different veterinary students (S. aureus and S. intermedius), the refrigerator used to store drugs (S. intermedius), and the counter surface in the hospital (S. intermedius). S. intermedius was
Gram-negative rods

Escherichia coli

Proteus mirabilis

Hafnia alvei

Enterobacter cloacae

Klebsiella pneumoniae

Pragia fontium

Salmonella sp.

Pseudomonas aeruiginosa

Citrobacter diversus

Ewingella americana

Kluyvera sp.

12

8

8

5

4

2

1

1

1

1

1

Coagulase-positive Staphylococcus

Staphylococcus intermedius

Staphylococcus aureus
6

1 
from a barred owl during its pre-release examination was susceptible to all of the antimicrobials. This animal likewise did not receive antibiotic therapy during its hospitalization.

\section{Discussion}

The prevalence of ARB in this study was greater than 25 percent, and confirms that many patients admitted to the WHL harbor antimicrobial resistant bacteria. There was no significant difference in the isolation of ARB from raptors and the other birds sampled in this study. Because raptors are generally in the top tier of the food web within their ecosystems, it is possible that they might become colonized with bacteria from the flora of their prey. Although there have not been any direct studies to confirm the transfaunation of the microflora from prey to raptors, pathogenic organisms are occasionally transferred via this route (Forbes and ParryJones 1996). Thus, it is possible that animals in the top trophic levels might be more likely to accrue ARB from their diet. The absence of a difference in this study may be attributed to the fact that many of the non-raptorial birds were also omnivores or carnivores. A larger sample size differentiating birds based on their feeding strategies would be necessary to determine if the prevalence of $\mathrm{ARB}$ in birds is directly related to diet.

There were no significant differences in the likelihood of isolating resistant bacteria when comparing among the various antibiotics, except for trimethoprim sulfadimethoxine (Table 7). Based on the 95 percent $\mathrm{CI}$, resistance to trimethoprim sulfadimethoxine is less likely than resistance to ami-
Table 3. Intermediate susceptibility patterns recorded for bacteria isolated from the wildlife hospital environment.

Environmental sample Bacterial isolate Intermediate resistance

$\begin{array}{lll}\text { Air } & \text { E. cloacae } & \text { GM } \\ \text { Cage } & \text { H. alvei } & \text { TIC } \\ \text { Cage } & \text { H. alvei } & \text { CTX, CIP } \\ \text { Counter surface } & \text { E. cloacae } & \text { CTX, C, GM } \\ \text { Counter surface } & \text { S. } \text { intermedius } & \text { C } \\ \text { Drug refrigerator } & \text { S. intermedius } & \text { C, CIP, ENO, GM } \\ \text { Exam table } & \text { E. coli } & \text { AM, D, GM, PIP } \\ \text { Exam table } & \text { H. alvei } & \text { TIC } \\ \text { Food refrigerator } & \text { E. cloacae } & \text { CIP } \\ \text { Food refrigerator } & \text { K. pneumoniae } & \text { CTX, C, CIP, ENO, TIC } \\ \text { Food refrigerator } & \text { H. alvei } & \text { D, TIC } \\ \text { Gloves } & \text { K. pneumoniae } & \text { GM } \\ \text { Orphan food } & \text { P. mirabilis } & \text { GM } \\ \text { Orphan food } & \text { P. mirabilis } & \text { AM, C, GM } \\ \text { Student hands } & \text { S. aureus } & \text { CTX, CIP } \\ \text { Student hands } & \text { S. intermedius } & \text { SXT }\end{array}$

Table 4. Complete resistance patterns recorded for bacteria isolated from the wildlife hospital environment.

$\begin{array}{lll}\text { Environment sample } & \text { Bacterial isolate } & \text { Complete resistance } \\ \text { Air } & \text { E. cloacae } & \text { AM, D } \\ \text { Cage } & \text { H. alvei } & \text { AM, CAZ } \\ \text { Cage } & \text { H. alvei } & \text { CAZ } \\ \text { Counter surface } & \text { E. cloacae } & \text { AM, D } \\ \text { Drug refrigerator } & \text { H. alvei } & \text { CTX, CAZ } \\ \text { Drug refrigerator } & \text { S. intermedius } & \text { AM, CTX, CAZ, PIP, TIC } \\ \text { Exam table } & \text { H. alvei } & \text { AM, CTX, CAZ, PIP } \\ \text { Floor } & \text { P. mirabilis } & \text { PIP, TIC } \\ \text { Floor } & \text { P. fonium } & \text { CTX, CAZ, C } \\ \text { Food refrigerator } & \text { E. cloacae } & \text { CTX, CAZ, C, PIP, TIC } \\ \text { Food refrigerator } & \text { H. alvei } & \text { CTX, CAZ } \\ \text { Food refrigerator } & \text { K. pneumoniae } & \text { AM, CAZ, GM } \\ \text { Gloves } & \text { K. pneumoniae } & \text { AM, CTX, CAZ, C, CIP, } \\ & & \text { D, ENO, PIP, TIC, SXT } \\ \text { Orphan food } & \text { P. mirabilis } & \text { D } \\ \text { Student hands } & \text { S. aureus } & \text { CAZ, PIP, TIC }\end{array}$

Key to Antibiotic Abbreviations.

$\begin{array}{llr}\text { AM }=\text { amikacin } & \text { CIP = ciprofloxacin } & \text { PIP = piperacillin } \\ \text { CTX = cefatoxime } & \mathrm{D}=\text { doxycycline } & \text { TIC = ticaricillin } \\ \text { CAZ = ceftazidime } & \text { ENO = enrofloxacin } & \text { SXT }=\text { trimethoprim } \\ \mathrm{C}=\text { chloramphenicol } & \text { GM }=\text { gentamicin } & \text { sulfadimethoxine }\end{array}$

kacin, ceftazidime, chloramphenicol, and doxycycline. Doxycycline is a commonly used antibiotic in human and veterinary medicine. Resistance to this compound 
Table 5. Intermediate susceptibility patterns recorded for bacteria isolated from wildlife.

\begin{tabular}{|lll|}
\hline Wildlife species & Bacterial isolate & $\begin{array}{l}\text { Intermediate } \\
\text { resistance }\end{array}$ \\
American crow & E. coli & C, D, GM \\
American crow & C. diversus & AM, D, PIP \\
Great blue heron & E. coli & AM, GM, D \\
Mississippi kite & E. coli & D \\
Pigeon & E. coli & PIP \\
\hline
\end{tabular}

Table 6. Complete resistance patterns recorded for bacteria isolated from wildlife.

\begin{tabular}{|lll|}
\hline Wildlife sample & Bacterial isolate & $\begin{array}{l}\text { Complete } \\
\text { resistance }\end{array}$ \\
American crow & P. mirabilis & D \\
Broad-winged hawk & E. cloacae & C, D \\
Cattle egret & E. coli & D, ENO \\
Mississippi kite & P. mirabilis & D \\
Mississippi kite & E. coli & D \\
Mississippi kite & E. coli & AM, D, ENO \\
Mute swan & E. coli & CIP, D, ENO, \\
& & GM, PIP, \\
Northern cardinal & E. coli & TIC, SXT \\
Pigeon & P. fontium & CTX, CAZ \\
Red-tailed hawk & S. intermedius & CAZ \\
(perm. resident) & & \\
Red-tailed hawk & P. mirabilis & C, D \\
Red-tailed hawk & Klyuvera sp. & AM \\
Eastern screech owl & E. coli & D \\
Virginia opossum & P. mirabilis & C, D \\
\hline
\end{tabular}

would not be unexpected, as compared to chloramphenicol, which is rarely used in human or veterinary medicine because of the possible negative side effect of aplastic anemia. This study also indicated resistance to synthetic antibiotics, such as enrofloxacin.

Based on the results of this study, several changes were made regarding the maintenance of the hospital. Historically, two percent chlorhexidine solution and Roccal-D Plus ${ }^{\circledR}$ (1:256) (Pharmacia and Upjohn, Co., Kalamazoo, MI) were used to disinfect the wildlife cages, exam tables, and counter surfaces. The cages were cleaned at least once a day, and the exam tables and counter surfaces were cleaned after every use. Today, these same disinfectant protocols are used, but five percent sodium hypochlorite is used as well. The leather gloves used for restraining raptors were historically used until the stitches in the seams fell out or the gloves were contaminated while handling an animal with a contagious disease (e.g., poxvirus). Under our new guidelines, the gloves are also disinfected with the five percent sodium hypochlorite spray, and discarded after one month. The surfaces of the drug and food refrigerators were generally cleaned when necessary. Today, they are disinfected with chlorhexidine and sodium hypochlorite on a weekly basis.

Because ARB were found in food fed to the patients, a review of the methods used by those responsible for feeding was conducted. The food was often being left out of the refrigerator for extended periods, and it was not covered when placed into the refrigerator. It is now kept in sealed containers, and labeled with the date and time when it was prepared. Finally, latex or nitrile examination gloves are also made available when examining and treating wildlife. This practice is important not only to minimize the transmission of ARB, but other zoonotic pathogens, such as West Nile virus. After handling any patient, washing hands thoroughly with warm soapy water is required.

One of the problems encountered at wildlife facilities such as the WHL is the continual cycle of new personnel rotating through the facility. This frequently leads to a breakdown in management protocols. To counter this, signs have been posted to remind all personnel of the importance of the biosecurity protocols.

The transfer of ARB from one patient to another is of special concern in human hospitals,

Table 7. Prevalence and 95 percent CI for (intermediate or complete) antimicrobial resistance for Gram negative isolates collected from wildlife and the hospital environment.

\begin{tabular}{|lccl|}
\hline Antimicrobial & $n$ & prevalence & $95 \% C I$ \\
Amikacin & 61 & $41 \%$ & $29-53$ \\
Cefatoxime & 61 & $31 \%$ & $19-43$ \\
Ceftazidime & 61 & $34 \%$ & $22-46$ \\
Chloramphenicol & 61 & $44 \%$ & $32-57$ \\
Ciprofloxacin & 61 & $18 \%$ & $8-29$ \\
Doxycycline & 61 & $36 \%$ & $24-48$ \\
Enrofloxacin & 30 & $20 \%$ & $6-34$ \\
Gentamicin & 61 & $21 \%$ & $11-31$ \\
Piperacillin & 61 & $26 \%$ & $15-37$ \\
Ticaricillin & 61 & $26 \%$ & $15-37$ \\
Trimethoprim sulfadimethoxine & 61 & $11 \%$ & $3-19$ \\
\hline
\end{tabular}


as well as to wildlife veterinarians. Originally, this study was conceived as a means to determine whether wildlife can develop ARB as a result of treatment or acquire it from nosocomial infections. Unfortunately, during the sampling period, few patients were rehabilitated to release. However, based on the results of the prevalence data, it is possible that rehabilitation facilities contribute to the dissemination of ARB when they release wildlife.

The results of this study suggest that veterinarians and wildlife rehabilitators must be judicious in the application of antibiotics. The primary method for diminishing the development of ARB is to limit the use of antibiotics to those cases with a confirmed bacterial disease or those that are highly suspicious. By reducing the use of these compounds, we will diminish the selection for ARB that occurs in the microflora. In addition, individuals working with wildlife should take special precautions within their rehabilitation environment by using appropriate disinfectants, routinely cleaning all of the fixed surfaces within the hospital, and properly storing and discarding food products fed to the wildlife.

\section{ACKNOWLEDGEMENTS}

The authors thank Merck-Merial for their support of the Student Research Elective program, which funded this project.

\section{LITERATURE CITED}

Bailey, T. A., C. Silvanose, U. Wernery, J. H. Samour, and J. Naldo. 1998. Antimicrobial resistance and minimum inhibitory concentrations of bacteria isolated from bustards in the United Arab Emirates. Avian Diseases, 42:690-697.

Borchardt, J. K. Bacteria rapidly develop resistance to new antibiotic. The Scientist-Daily News. <www. the-scientist.com>. April 20, 2001.

Braude, R., R. C. Campbell, I. A. Lucas, J. R. Luscombe, K. L. Robonson, J. H. Taylor. 1955. Antibiotics and endocrine stimulants as promoters of growth in fattening pigs. British Journal of Nutrition, 9(2):191-196.

Bren, L. 2002. Battle of the bugs: fighting antibiotic resistance. FDA Consumer, 36(4): <www.fda.gov/ fdac/402_toc.html>.

Cooke, C. L., R. S. Singer, S. S. Jang, and D. C Hirsch. 2002. Enrofloxacin resistance in Escherichia coli isolated from dogs with urinary tract infections. Journal of the American Veterinary Medical Association, 220(2):190-192.

Forbes, N., and J. Parry-Jones. 1996. Management and Husbandry. In Manual of Raptors, Pigeons, and Waterfowl. P. H. Beynon, N. A. Forbes, N. H. Harcourt-Brown (eds). Pp. 116-128. Ames, IA: Iowa State University Press.

Hileman, B. Debate over health hazards of putting antibiotics in animal feed heats up in the USA. Chemical and Engineering News, October 25, 1999.

Hudson, C., C. Quist, M. D. Lee, K. Keyes, S. V. Dodson, C. Morales, S. Sanchez, D. G. White, and J. J. Maurer. 2000. Genetic relatedness of Salmonella isolates from nondomestic birds in Southeastern United States. Journal of Clinical Microbiology, 38(5):1860-1865.

Kimpe, A., A. Decostere, A. Martel, F. Haesebrouck, and L. A. Devriese. 2002. Prevalence of antimicrobial resistance among pigeon isolates of Streptococcus gallolyticus, Escherichia coli, and Salmonella enterica serotype Typhimurium. Avian Pathology, 31:393-397.

The National Committee for Clinical Laboratory Standards. 1993. Methods for Dilution Antimicrobial Susceptibility Tests for Bacteria that Grow Aerobically. $3^{\text {rd }}$ ed. NCCLS, Document M7-A3.

The National Committee for Clinical Laboratory Standards. 2002. Performance Standards for Antimicrobial Disk and Dilution Susceptibility Tests for Bacteria Isolated from Animals. $2^{\text {nd }}$ ed. NCCLS Document M31-A2.

O'Brien, T. F. 2002. Emergence, spread, and environmental effect of antimicrobial resistance: how use of an antimicrobial anywhere can increase resistance to any antimicrobial anywhere else. Clinical Infectious Diseases, 34(3):578-584.

O'Rourke, K. 2003. Antimicrobial resistance in wildlife: it's making a bigger splash than you think. Journal of the American Veterinary Medical Association, 223(6):756-757.

Sims, M. D., K. A. Dawson, K. E. Newman, P. Spring, and D. M. Hoogell. 2004. Effects of dietary manna oligosaccharides, bacitracin methylene disalicylate, or both on the live performance and intestinal microbiology of turkeys. Poultry Science, 83(7):1148-1154.

van Belle, G., and S. P. Millard. 1998. STRUTS: Statistical rules of thumb. <www.nrcse.washington.edu>. Seattle, WA. Pp. 3-13. (․ㅛ상 